The character of the change of $\alpha$ with temperature for the group of haloids of potassium, sodium and lithium which crystallize in lattices of the same type is fairly similar. However, it appears from data already given by Eucken and Dannöhl that the expansion of compounds which are more easily polarized shows a tendency to increase from $0 \cdot 6 T_{s}$.

The replacement of the alkali metals by the strongly deforming ion of silver causes the appearance of a large dependence of the expansion coefficient on the temperature, when with increase of the amplitude of the thermal motion the influence of the polarizing forces increases. Silver chloride appears to represent the limiting case, since silver iodide already crystallizes in a different type of lattice.

As a characteristic of the condition of the lattice of these compounds at high temperatures, it is of interest to recall the following jumps in the electrical conductivities at the melting point : sodium chloride, 3,000 ; silver chloride, 30 ; and silver bromide, 5 .

$$
\text { P. G. Strelkov. }
$$

Physico-Technical Institute of Ural. Leningrad.

${ }^{1}$ Eucken, A., and Dannöhl, w., Z. Elektrochem., 40, 814 (1934).

\section{The Low-temperature Transformation of Heavy Ammonium Chloride}

After having studied the low-temperature transformations of the ammonium halides, it was of interest to examine the influence of a substitution of the ordinary hydrogen in the ammonium group by heavy hydrogen. We started with $\mathrm{ND}_{4} \mathrm{Cl}$, obtained in the following way, working in evacuated apparatus. $\mathrm{DCl}$ prepared in a vacuum from $\mathrm{D}_{2} \mathrm{O}(99.97$ per cent) and phosphorus pentachloride, was after several distillations finally dissolved in $\mathrm{D}_{2} \mathrm{O}$. $\mathrm{ND}_{3}$ prepared from $\mathrm{D}_{2} \mathrm{O}$ and magnesium nitride $\left(\mathrm{Mg}_{3} \mathrm{~N}_{2}\right)$ and also several times distilled was dissolved in the DCl solution. This solution was evaporated in a stream of dry pure nitrogen, and then the solid $\mathrm{ND}_{4} \mathrm{Cl}$ was dried in a vacuum desiccator over phosphorus pentoxide. No impurities could be detected in the $\mathrm{ND}_{4} \mathrm{Cl}$ prepared in this way.

With ordinary ammonium chloride our statical dilatometrical investigations showed ${ }^{1}$ at about $-30^{\circ}$ a heterogeneous transformation, together with the phenomenon of heterogeneous hysteresis, within a temperature range of $0 \cdot 3^{\circ}$. The result obtained with heavy ammonium chloride is quite different. The transition is a continuous one; the steepest part of the $V, T$ curve appears in the neighbourhood of about $-24^{\circ}$ and hysteresis has disappeared. This change in character of the transition is very remarkable. The shift of the transition to higher temperature was expected, but the change of a heterogeneous transformation into a homogeneous one was surprising, and the disappearance of the phenomenon of hysteresis, significant. In continuing our investigations with the other halides, we hope to reach a fuller understanding of the interesting phenomenon of hysteresis.

A. Smits.

G. J. Muller.

Laboratory of Inorganic and

Physical Chemistry,

University, Amsterdam. April 8.

'Z. phys. Chem., A, 166, 97 (1933).

\section{Magnetic Susceptibility of Mercury Vapour}

I HAVE measured the susceptibility of mercury vapour by means of a method already described ${ }^{1}$.

The atomic susceptibility of mercury has been found to be

$$
\chi_{a}=-(78 \pm 7) \times 10^{-6} .
$$

The susceptibility of the $\mathrm{Hg}++$ ion had been measured several times by different investigators, and its most plausible experimental value ${ }^{2}$ is

$$
\chi_{j}=-40.4 \times 10^{-6} .
$$

Thus for the first time we are able to compare $\chi_{a}$ with $\chi_{j}$ and to compute the fraction of the dia. magnetic susceptibility given by the two valence electrons of mercury :

$$
\chi_{e}=\chi_{a}-\chi_{j}=-38 \times 10^{-6} .
$$

We see that the diamagnetism of the two valence electrons of mercury is nearly equal to that of the ion. This result is rather important, because it suggests an explanation of the well-known fact that the diamagnetism of atoms is greatly influenced by the formation of molecules, as was observed, for example, in organic compounds by Pascal.

In the following table we give a comparison of the observed susceptibility of the mercury atom with that calculated by different approximate theoretical methods.

$\chi a \times 10^{6}$.

\begin{tabular}{|c|c|c|c|}
\hline $\begin{array}{c}\text { Sommerfeld } \\
\text { calculated }\end{array}$ & $\begin{array}{c}\text { Gombas } \\
\text { calculated }\end{array}$ & $\begin{array}{c}\text { Slater }^{5} \\
\text { calculated }\end{array}$ & $\begin{array}{c}\text { Experimental } \\
\text { value }\end{array}$ \\
\cline { 1 - 3 } & $133 \cdot 3$ & $84 \cdot 6$ & 78 \\
\hline
\end{tabular}

As may be seen from this table, the calculation carried out by Slater's method gives the most consistent results.

A detailed description of this work will appear in the Phys. Z. Sow. Union.

Phys. Technical Institute

J. S. SHUR.

of the Ural, Sverdlovsk.

'Jaanus, R., and Shur, J. S., Sow. Phys., 7, 19 (1935); 7, 501 (1935).

${ }^{2}$ Kido, K., Sci. Rep. Tôhoku Univ., 22, 834 (1933).

sommerfeld, A., Z. Phys., 78, 283 (1932).

4 Gombas, P., Z. Phys., 87, 57 (1933).

' Slater, J. C., Phys. Rev., 36, 57 (1930).

\section{Phosphorescence of the Sea}

Wres sailing off the western Scottish coast, I found it possible to predict with certainty phosphorescent nights owing to a nipping sensation on the backs of my fingers after immersion in the sea. This seems to indicate some marine organism. As Dr. R. E. D. Clark's letter in Nature of April 3 suggests, the phosphorescence is doubtless due "to the agitation of phosphorescent marine organisms".

If a boat-hook is pressed gently downwards into the water on a suitable occasion, there is little observable effect. The slightest jerk, however, that violently disturbs the water, at once produces luminosity but only in the disturbed region. During a very squally night when anchored in Mallaig Bay, I saw a beautiful display. The sea was black but the crest of every small wave that broke was brilliantly 